\title{
No evidence of a significant role for CTLA-4 in multiple sclerosis
}

Richard H. Roxburgh ${ }^{1,2}$, Stephen Sawcer ${ }^{1}$, Mel Maranian ${ }^{1}$, Shaun

Seaman ${ }^{3}$, Anke Hensiek ${ }^{1}$, Taiwai Yeo ${ }^{1}$, Jackie Deans ${ }^{1}$, Alastair

Compston ${ }^{1}$

${ }^{1}$ Department of Clinical Neurosciences, Cambridge University, UK

${ }^{2}$ Neurology Department, Auckland City Hospital, Auckland, New

Zealand

${ }^{3}$ Max Planck Institute for Psychiatry, Munich, Germany.

Corresponding Author: Prof. Alastair Compston

Department of Clinical Neurosciences,

Cambridge University,

Addenbrooke's Hospital,

CB2 2QQ

Cambridge,

UK

Phone: +44 1223217091

Fax: +44 1223336941

Email: alastair.compston@medschl.cam.ac.uk

Running Title: Multiple sclerosis and CTLA-4 


\section{Abstract}

Variation in the cytotoxic T-lymphocyte-associated protein 4 (CTLA4) gene plays a significant role in determining susceptibility to autoimmune thyroid disease and type 1 diabetes. Its role in multiple sclerosis is more controversial. In order to explore this logical candidate more thoroughly we genotyped 771 multiple sclerosis trio families from the United Kingdom for the 3'untranslated region variable number tandem repeat, the CT60 single nucleotide polymorphism (SNP) and five haplotype-tagging SNPs. No individual marker or common haplotype showed evidence of association with disease. These data suggest that any effect of CTLA-4 on multiple sclerosis susceptibility is likely to be very small.

Key words: multiple sclerosis, cytotoxic T-lymphocyte-associated protein 4, CTLA-4, genetic association, disease severity 


\section{Introduction}

Variation in the cytotoxic T-lymphocyte-associated protein 4 (CTLA4) gene plays a significant role in determining susceptibility to autoimmune thyroid disease and type 1 diabetes (Ueda et al., 2003). In multiple sclerosis its influence on disease susceptibility (Ligers et al., 1999, Fukazawa et al., 1999, Harbo et al., 1999, Rasmussen et al., 2001, Dyment et al., 2002, Maurer et al., 2002, Kantarci et al., 2003, van Veen et al., 2003, Alizadeh et al., 2003, Teutsch et al., 2004) and course (Masterman et al., 2002, Maurer et al., 2002) has been studied in a variety of populations. A trend towards association with the common short ( 8 repeat) allele of the variable number tandem repeat (VNTR) polymorphism in the 3' untranslated region (3'UTR) of the gene has been reported (Kantarci et al., 2003). In nine other case control studies (Teutsch et al., 2004) no consistent results have emerged. We systematically studied the gene in a large cohort of multiple sclerosis trio families (an affected individual and both parents). We studied the 3'UTR VNTR, and six single nucleotide polymorphisms (SNPs): CT60, which was identified by Ueda et al. (Ueda et al., 2003) as showing the strongest linkage disequilibirum with type 1 diabetes and thyroid disease, and five haplotype tagging SNPs (htSNPs) (T-1722C, A-1661G, C-658T, C-319T and A49G) described by Johnson et al. (Johnson et al., 2001) See figure 1. 


\section{Patients and Methods}

\section{Patients}

The 771 patients included in this study were recruited throughout the UK. All patients satisfied the Poser criteria (Poser et al., 1983) for definite $(95 \%)$, or probable (5\%) multiple sclerosis; $60 \%$ had relapsing, $31 \%$ secondary progressive and $9 \%$ primary progressive multiple sclerosis. The mean age at diagnosis was 30.9 years; female to male ratio was 3.0:1. All patients and their parents gave written informed consent.

\section{Genotyping}

All primers are listed in table 1.

\section{3'UTR VNTR}

The 3'UTR VNTR was genotyped according to previously described methods (Nistico et al., 1996). PCR was performed in $10 \mu$ reactions using: $50 \mathrm{ng}$ genomic DNA, $0.5 \mathrm{U}$ Taq DNA polymerase, $200 \mu \mathrm{M}$ dNTPs, 1.6x PCR Buffer and $2 \mathrm{mM} \mathrm{MgCl} 2,0.125 \mu \mathrm{M}$ primers. Reactions were carried out on an Applied Biosystems (ABI) 9700 Integrated Thermal Cycler using a $58{ }^{\circ} \mathrm{C}$ touchdown protocol (Don et al., 1991). The products were separated on an ABI Prism 3700 DNA analyser. Genotyping was completed using ABI GENESCAN and GENOTYPER software. 


\section{CT60}

The CT60 SNP was genotyped using a TaqMan Assay By Design performed according to the manufacturers standard conditions using ABI 9700 Integrated Thermal Cycler for PCR and a 7900 HT Sequence Detection System with Allelic Discrimination Software for genotyping.

\section{Haplotype Tagging SNPs}

The htSNPs were genotyped using a specifically designed multiplex SNaPshot assay performed according to the manufacturers standard conditions. Two primary PCR fragments were amplified the first encompassing SNPs T-1722C and A-1661G, and the second SNPs C658T, C-319T and A49G (figure 1). The products from these amplifications were combined in equal volumes prior to primer extension. Primer extension products were separated and sized on a 3700 DNA analyser

\section{Statistical analysis}

Evidence for association with susceptibility was sought using the TRANSMIT program (Clayton, 1999) to perform transmission/disequilibirum testimg (TDT). Chi square was used to compare haplotype frequencies between primary progressive and bout onset patients. Disease severity was measured using the Multiple Sclerosis Severity Score (MSSS) (Roxburgh et al., 2005), and multiple linear regression was used to search for evidence of association with severity. Prior to analysis, Hardy Weinberg equilibrium was confirmed 
for each marker using the PEDSTATS program; genotyping errors were identified and excluded using the PEDCHECK program (O'Connell and Weeks, 1998).

\section{Results}

\section{Disease Susceptibility}

TDT analysis revealed no statistically significant evidence for association of any of the SNPs or haplotype tagging haplotypes (table 2). There was a trend to over-transmission of the 8 repeat allele of the 3'UTR VNTR and under transmission of the CT60 G allele overrepresented in Graves' disease and type 1 IDDM over. The six common haplotypes occurred in a similar frequency to that previously reported (Johnson et al., 2001) and accounted for $99.7 \%$ of observed haplotypes.

We also analysed the data from all seven markers combined using TRANSMIT. No statistically significant evidence for association was seen with any of the common haplotypes or in a global analysis. A trend towards over-transmission of both haplotypes containing the A allele of CT60 (undertransmitted in IDDM and autoimmune thyroid disease) was seen. These haplotypes also contain the 8 repeat allele of the 3'UTR VNTR.

Alizadeh et al. (Alizadeh et al., 2003) have suggested an interaction between the third htSNP (C-658T) and HLA DR15 status with over- 
transmission of the $\mathrm{C}$ allele only amongst DR 15 positive patients. We stratified the available data for this marker in the $716(93 \%)$ families where the DR15 status of the index case was known. Transmission of the $\mathrm{C}$ allele at -658 was not significantly distorted and, in fact, we observed a trend toward under-transmission of this allele, which was similar in both the HLA DR15 positive and negative patients.

\section{Disease Course}

Disease course was known in 744 patients. We could deduce precise htSNP haplotypes in $43 / 72$ patients with primary progressive disease and 550/672 patients with bout onset disease. Using these data we were unable to confirm the previous finding of an association between haplotypes containing the C allele at - C319G and the G allele at A49G (allele 1 of htSNPs $4 \&$ allele 2 of htSNP5) with primary progressive disease (Masterman et al., 2002, Maurer et al., 2002): proportions of such haplotypes were $37.7 \%$ amongst primary progressive patients and $36.2 \%$ amongst bout onset cases $(p=0.40)$. Homozygosity for these haplotypes was similarly non-discriminative, occurring in $14.3 \%$ of primary progressive and $13.3 \%$ of bout onset patients $(p=0.84)$.

\section{Disease Severity}

Excluding the 61 patients whose disability was assessed at a time of relapse $(n=59)$ or within the first year from disease onset $(n=2)$ the average EDSS in the remaining 710 index cases was 4.5 and the mean duration of disease 12.6 years. Within the cohort, the mean MSSS 
(Roxburgh et al., 2005) was 5.36. None of the individual

polymorphisms or common haplotypes formed by the htSNPs was

associated with disease severity $(p>0.36$, multiple linear regression).

\section{Discussion}

We have comprehensively analysed the variation from the CTLA- 4 gene in a large cohort of multiple sclerosis trio families and found no evidence for association with any marker or common marker haplotype. A trend towards over-transmission of the 8 repeat allele from the 3'UTR VNTR (Kantarci et al., 2003) was seen. Other previously described findings of an epistatic interaction between the htSNP C-658T and HLA DR15, and association between haplotypes of the $-\mathrm{C} 319 \mathrm{G}$ and A49G SNPs and disease course, were not confirmed. Analysis of the CT60 SNP revealed a trend to under transmission of the common $G$ allele in contrast to the data from Graves' disease and type 1 diabetes. These results suggest that any role of CTLA- 4 in multiple sclerosis is likely to be very small, and further suggest that if such an effect exists it is not determined by the $\mathrm{G}$ allele of the CT60 variant which is so important for other autoimmune diseases. This interpretation is consistent with the results of a meta-analysis of previous studies of the A49G SNP (Teutsch et al., 2004).

If the trend towards over transmission of the A allele from CT60 were confirmed this would indicate that different variants of CTLA-4 may 
predispose to different autoimmune diseases: $G$ allele haplotypes to thyroid disease and diabetes; and A allele haplotypes to multiple sclerosis. This would not be the first time that a dichotomous relationship between thyroid disease and multiple sclerosis has been reported. One third of patients with multiple sclerosis treated successfully with CAMPATH $1 \mathrm{H}$ (a monoclonal antibody to CD52) go on to develop Graves' disease. This switch in autoimmune response reflects a change from a Th1 to a Th2 (Coles et al., 1999) cytokine profile. A hypothesis worthy of consideration is that patients who do and do not make this switch differ at the CTLA-4 locus (especially CT60).

Although the use of carefully developed tagging SNPs has allowed us to analyse all the common haplotypes, it is still possible that others not directly tested are relevant and have been missed. Future studies of this gene in multiple sclerosis will need to be very much larger than the study presented here if they are to have power to demonstrate relevance of this gene. 


\section{Acknowledgements}

This work was supported by the Wellcome Trust, UK. There was no conflict of interest.

\section{References}

Alizadeh, M., Babron, M. C., Birebent, B., Matsuda, F., Quelvennec, E., Liblau, R., Cournu-Rebeix, I., Momigliano-Richiardi, P., Sequeiros, J., Yaouanq, J., Genin, E., Vasilescu, A., Bougerie, H., Trojano, M., Martins Silva, B., Maciel, P., Clerget- Darpoux, F., Clanet, M., Edan, G., Fontaine, B. and Semana, G. 2003. Genetic interaction of CTLA-4 with HLA-DR15 in multiple sclerosis patients. Ann Neurol, 54, 119- 22.

Clayton, D. 1999. A generalization of the transmission/disequilibrium test for uncertain-haplotype transmission. Am JHum Genet, 65, $1170-7$.

Coles, A. J., Wing, M., Smith, S., Coraddu, F., Greer, S., Taylor, C., Weetman, A., Hale, G., Chatterjee, V. K., Waldmann, H. and Compston, A. 1999. Pulsed monoclonal antibody treatment and autoimmune thyroid disease in multiple sclerosis. Lancet, 354, $1691-5$.

Don, R. H., Cox, P. T., Wainwright, B. J., Baker, K. and Mattick, J. S. 1991. 'Touchdown' PCR to circumvent spurious priming during gene amplification. Nucleic Acids Research, 19, 4008. 
Dyment, D. A., Steckley, J. L., Willer, C. J., Armstrong, H., Sadovnick, A. D., Risch, N. and Ebers, G. C. 2002. No evidence to support CTLA- 4 as a susceptibility gene in MS families: the Canadian Collaborative Study. J Neuroimmunol, 123, $193-8$.

Fukazawa, T., Yanagawa, T., Kikuchi, S., Yabe, I., Sasaki, H., Hamada, T., Miyasaka, K., Gomi, K. and Tashiro, K. 1999. CTLA-4 gene polymorphism may modulate disease in Japanese multiple sclerosis patients. J Neurol Sci, 171, 49- 55.

Harbo, H. F., Celius, E. G., Vartdal, F. and Spurkland, A. 1999. CTLA4 promoter and exon 1 dimorphisms in multiple sclerosis. Tissue Antigens, 53, 106- 10.

Johnson, G. C., Esposito, L., Barratt, B. J., Smith, A. N., Heward, J., Di Genova, G., Ueda, H., Cordell, H. J., Eaves, I. A., Dudbridge, F., Twells, R. C., Payne, F., Hughes, W., Nutland, S., Stevens, H., Carr, P., Tuomilehto- Wolf, E., Tuomilehto, J., Gough, S. C., Clayton, D. G. and Todd, J. A. 2001. Haplotype tagging for the identification of common disease genes. Nat Genet, 29, 233-7.

Kantarci, O. H., Hebrink, D. D., Achenbach, S. J., Atkinson, E. J., Waliszewska, A., Buckle, G., McMurray, C. T., de Andrade, M., Hafler, D. A. and Weinshenker, B. G. 2003. CTLA4 is associated with susceptibility to multiple sclerosis. J Neuroimmunol, 134, $133-41$.

Ligers, A., Xu, C., Saarinen, S., Hillert, J. and Olerup, O. 1999. The CTLA- 4 gene is associated with multiple sclerosis. $J$ Neuroimmunol, 97, $182-90$. 
Masterman, T., Ligers, A., Zhang, Z., Hellgren, D., Salter, H., Anvret, M. and Hillert, J. 2002. CTLA4 dimorphisms and the multiple sclerosis phenotype. J Neuroimmunol, 131, 208-12.

Maurer, M., Ponath, A., Kruse, N. and Rieckmann, P. 2002. CTLA4 exon 1 dimorphism is associated with primary progressive multiple sclerosis. J Neuroimmunol, 131, 213- 5.

Nistico, L., Buzzetti, R., Pritchard, L. E., Van der Auwera, B., Giovannini, C., Bosi, E., Larrad, M. T., Rios, M. S., Chow, C. C., Cockram, C. S., Jacobs, K., Mijovic, C., Bain, S. C., Barnett, A. H., Vandewalle, C. L., Schuit, F., Gorus, F. K., Tosi, R., Pozzilli, P. and Todd, J. A. 1996. The CTLA- 4 gene region of chromosome 2q33 is linked to, and associated with, type 1 diabetes. Belgian Diabetes Registry. Hum Mol Genet, 5, 1075 - 80.

O'Connell, J. R. and Weeks, D. E. 1998. PedCheck: a program for identification of genotype incompatibilities in linkage analysis. Am J Hum Genet, 63, 259- 66.

Poser, C. M., Paty, D. W., Scheinberg, L., McDonald, W. I., Davis, F. A., Ebers, G. C., Johnson, K. P., Sibley, W. A., Silberberg, D. H. and Tourtellotte, W. W. 1983. New diagnostic criteria for multiple sclerosis: guidelines for research protocols. Ann Neurol, 13, $227-31$.

Rasmussen, H. B., Kelly, M. A., Francis, D. A. and Clausen, J. 2001. CTLA4 in multiple sclerosis. Lack of genetic association in a European Caucasian population but evidence of interaction with HLA-DR2 among Shanghai Chinese. J Neurol Sci, 184, 143- 7. 
Roxburgh, R. H., Seaman, S. R., Masterman, T., Hensiek, A. E., Sawcer, S. J., Vukusic, S., Achiti, I., Confavreux, C., Coustans, M., le Page, E., Edan, G., McDonnell, G. V., Hawkins, S., Trojano, M., Liguori, M., Cocco, E., Marrosu, M. G., Tesser, F., Leone, M. A., Weber, A., Zipp, F., Miterski, B., Epplen, J. T., Oturai, A., Sorensen, P. S., Celius, E. G., Lara, N. T., Montalban, X., Villoslada, P., Silva, A. M., Marta, M., Leite, I., Dubois, B., Rubio, J., Butzkueven, H., Kilpatrick, T., Mycko, M. P., Selmaj, K. W., Rio, M. E., Sa, M., Salemi, G., Savettieri, G., Hillert, J. and Compston, D. A. 2005. Multiple Sclerosis Severity Score: using disability and disease duration to rate disease severity. Neurology, 64, 1144-51.

Teutsch, S. M., Booth, D. R., Bennetts, B. H., Heard, R. N. and Stewart, G. J. 2004. Association of common T cell activation gene polymorphisms with multiple sclerosis in Australian patients. $J$ Neuroimmunol, 148, $218-30$.

Ueda, H., Howson, J. M., Esposito, L., Heward, J., Snook, H., Chamberlain, G., Rainbow, D. B., Hunter, K. M., Smith, A. N., Di Genova, G., Herr, M. H., Dahlman, I., Payne, F., Smyth, D., Lowe, C., Twells, R. C., Howlett, S., Healy, B., Nutland, S., Rance, H. E., Everett, V., Smink, L. J., Lam, A. C., Cordell, H. J., Walker, N. M., Bordin, C., Hulme, J., Motzo, C., Cucca, F., Hess, J. F., Metzker, M. L., Rogers, J., Gregory, S., Allahabadia, A., Nithiyananthan, R., Tuomilehto- Wolf, E., Tuomilehto, J., Bingley, P., Gillespie, K. M., Undlien, D. E., Ronningen, K. S., Guja, C., Ionescu- Tirgoviste, C., Savage, D. A., Maxwell, A. P., Carson, D. J., Patterson, C. C., 
Franklyn, J. A., Clayton, D. G., Peterson, L. B., Wicker, L. S., Todd, J. A. and Gough, S. C. 2003. Association of the T-cell regulatory gene CTLA4 with susceptibility to autoimmune disease. Nature, 423, 506- 11 .

van Veen, T., Crusius, J. B., van Winsen, L., Xia, B., Barkhof, F., Salvador Pena, A., Polman, C. H. and Uitdehaag, B. M. 2003. CTLA-4 and CD28 gene polymorphisms in susceptibility, clinical course and progression of multiple sclerosis. JNeuroimmunol, 140, 188-93. 


\section{Titles and Legends to Tables}

Table 1 Primer Sequences for CTLA- 4 analysis.

3'UTR VNTR = 3' untranslated region variable number tandem repeat. HtSNP = haplotype tagging single nucleotide polymorphism

Table 2 Susceptibility to multiple sclerosis and transmission of 3'UTR VNTR and CT60 alleles

3'UTR VNTR = 3' untranslated region variable number tandem repeat.

$p_{\text {uncorrected }}=\mathrm{p}$ value uncorrected for multiple testing; $\mathrm{SNP}=$ Single nucleotide polymorphism; htSNP = haplotype tagging SNP. In the haplotype list 1 indicates the commoner allele of each htSNP (i.e. respectively T,A,C,C,A); and 2 indicates the minor allele (i.e. respectively $\mathrm{C}, \mathrm{G}, \mathrm{T}, \mathrm{TG})$. 


\section{Titles and Legends to Figures}

\section{Figure 1}

Schematic structure of CTLA-4 gene showing position of polymorphisms and primary PCR amplimers.

Primary PCR amplimer 1 is $211 \mathrm{bp}$ in length and spans the first two htSNPs; Primary PCR amplimer 2 is 840 bp in length and spans htSNP 3, 4 and 5. htSNP = Haplotype tagging single nucleotide polymorphism, VNTR = Variable tandem repeat, $b p=$ base - pair 


\section{Table 1}

\begin{tabular}{|c|c|c|c|c|}
\hline & & Primer Sequence $\left(5^{\prime}-3^{\prime}\right)$ & $\begin{array}{l}\text { Product } \\
\text { Size } \\
\text { (bp) } \\
\end{array}$ & \\
\hline \multicolumn{2}{|c|}{ 3'UTR VNTR } & $\begin{array}{l}\text { FAM- GTG ATG CTA AAG GTT GTA TTG C } \\
\text { AAA ACA TAC GTG GCT CTA TGC AC }\end{array}$ & $84-132$ & \\
\hline \multicolumn{2}{|l|}{ CT60 } & $\begin{array}{l}\text { Forward: TGG AAG GTA TCC ATC CTC TTT CCT } \\
\text { Reverse: CAT GCC AAT TGA TTT ATA AAG GAC TGC TA } \\
\text { Probes: A/TTT GGG ATA TAA CGT GGG TTA }\end{array}$ & & \\
\hline \multicolumn{5}{|l|}{ SNaPshot } \\
\hline \multirow{2}{*}{\multicolumn{2}{|c|}{$\begin{array}{l}\text { Primary PCR } 1 \\
\text { Primary PCR } 2\end{array}$}} & CCA CTG GCT TCT GCT CCT AGC TCA AGC GCC AAC AAG & 211 & \\
\hline & & $\begin{array}{l}\text { GGG TTG GCT TTT CTT TGG ACC TTT GCA GAA GAC AGG } \\
\text { GA }\end{array}$ & 880 & \\
\hline \multicolumn{2}{|c|}{ Interrogating Primers: } & & $\begin{array}{l}\text { Product } \\
\text { Size } \\
\text { (bases) }\end{array}$ & $\begin{array}{l}\text { Concentratio } \\
\mathrm{n} \text { in } \\
\text { extension } \\
\text { step }\end{array}$ \\
\hline htSNP1: - 1722 & $\mathrm{~T}>\mathrm{C}$ & $\begin{array}{l}\text { TTT TTT TTT TTT TTC TAT CAT GAT CAT GGG TTT AGC } \\
\text { TG }\end{array}$ & 38 & $0.3 \mu \mathrm{M}$ \\
\hline htSNP2: - 1661 & $A>G$ & TTT TTT TCA GGA ACA TTT GTT TTT CAC TTT TT & 32 & $0.3 \mu \mathrm{M}$ \\
\hline htSNP3: - 658 & $\mathrm{C}>\mathrm{T}$ & CTT CTG CAA AAC CAG AGG CAG CTT CTT TTC & 30 & $3.0 \mu \mathrm{M}$ \\
\hline htSNP4: - 319 & $\mathrm{C}>\mathrm{T}$ & AGT CTC CAC TTA GTT ATC CAG ATC CT & 26 & $3.0 \mu \mathrm{M}$ \\
\hline htSNP5: +49 & $\mathrm{G}>\mathrm{A}$ & $\begin{array}{l}\text { TTT TTT TTT TTT TTT TTT TTC ACA AGG CTC AGC TGA } \\
\text { ACC TGG CT }\end{array}$ & 44 & $3.0 \mu \mathrm{M}$ \\
\hline
\end{tabular}




\section{Table 2}

\begin{tabular}{|c|c|c|c|c|c|c|}
\hline & $\begin{array}{c}\text { Genotype } \\
\text { Success Rate } \\
\text { N (\%) }\end{array}$ & Het (\%) & Observed & Expected & $x^{2}$ & Puncorrected \\
\hline 3'UTR VNTR & $740(96)$ & 0.63 & & & & \\
\hline 8 repeat allele & & & & & 2.85 & 0.09 \\
\hline $\begin{array}{l}17 \text { repeat } \\
\text { allele }\end{array}$ & & & & & 1.22 & 0.27 \\
\hline Other alleles & & & & & 0.77 & 0.38 \\
\hline \multicolumn{7}{|c|}{$\begin{array}{l}\text { SNPs: } \\
\text { (Transmission of Common allele) }\end{array}$} \\
\hline CT60 & $724(94)$ & 0.50 & 765 & 784 & 1.95 & 0.16 \\
\hline htSNP1 & 735 (95) & 0.13 & 1427 & 1418 & 1.27 & 0.26 \\
\hline htSNP2 & 735 (95) & 0.28 & 1273 & 1268 & 0.22 & 0.64 \\
\hline htSNP3 & $616(80)$ & 0.14 & 1166 & 1175 & 1.95 & 0.16 \\
\hline htSNP4 & $616(80)$ & 0.15 & 1175 & 1177 & 0.09 & 0.76 \\
\hline htSNP5 & $611(79)$ & 0.47 & 804 & 787 & 2.34 & 0.13 \\
\hline \multicolumn{7}{|c|}{ htSNP haplotypes } \\
\hline 1.1.1.1.1 & & & 570 & 557 & 1.3 & 0.24 \\
\hline 1.1.1.1.2 & & & 458 & 468 & 0.76 & 0.35 \\
\hline 1.2 .1 .2 .1 & & & 118 & 119 & 0.02 & 0.89 \\
\hline 1.1.2.1.1 & & & 119 & 111 & 1.6 & 0.22 \\
\hline 2.1.1.1.2 & & & 93 & 99 & 0.99 & 0.37 \\
\hline 1.2.1.1.1 & & & 118 & 122 & 0.23 & 0.60 \\
\hline Global & & & & & $\begin{array}{l}4.2(5 \\
\text { d.f. })\end{array}$ & 0.52 \\
\hline
\end{tabular}

